\title{
An Evidence-Based Health Care Knowledge Integration System: Assessment Protocol
}

Véronique Nabelsi ${ }^{1}$, BSc, MEng, PhD; Sylvain Croteau ${ }^{2}, \mathrm{MD}$

${ }^{1}$ Département des sciences administratives, Université du Québec en Outaouais, Gatineau, QC, Canada

${ }^{2}$ Hôpital de Gatineau, Centre intégré de santé et des services sociaux de l'Outaouais, Gatineau, QC, Canada

\section{Corresponding Author:}

Véronique Nabelsi, BSc, MEng, PhD

Département des sciences administratives

Université du Québec en Outaouais

Case postale 1250, Succursale Hull

Gatineau, QC, J8X 3X7

Canada

Phone: 18195953900 ext 1915

Email: veronique.nabelsi@uqo.ca

\begin{abstract}
Background: The rapid advancements in health care can make it difficult for general physicians and specialists alike to keep their knowledge up to date. In medicine today, there are deficiencies in the application of knowledge translation (KT) in clinical practice. Some medical procedures are not required, and therefore, no value is added to the patient's care. These unnecessary procedures increase pressures on the health care system's resources, reduce the quality of care, and expose the patients to stress and to other potential risks. KT tools and better access to medical recommendations can lead to improvements in physicians' decision-making processes depending on the patient's specific clinical situation. These tools can provide the physicians with the available options and promote an efficient professional practice. Software for the Evolution of Knowledge in MEDicine (SEKMED) is a technological solution providing access to high-quality evidence, based on just-in-time principles, in the application of medical recommendations for clinical decision-making processes recognized by community members, accreditation bodies, the recommendations from medical specialty societies made available through campaigns such as Choosing Wisely, and different standards or accreditive bodies.
\end{abstract}

Objective: The main objective of this protocol is to assess the usefulness of the SEKMED platform used within a real working clinical practice, specifically the Centre intégré de santé et des services sociaux de l'Outaouais in Quebec, Canada. To achieve our main objective, 20 emergency physicians from the Hull and Gatineau Hospitals participate in the project as well as 20 patient care unit physicians from the Hull Hospital. In addition, 10 external students or residents studying family medicine from McGill University will also participate in our study.

Methods: The project is divided into 4 phases: (1) orientation; (2) data synthesis; (3) develop and validate the recommendations; and (4) implement, monitor, and update the recommendations. These phases will enable us to meet our 6 specific research objectives that aim to measure the integration of recommendations in clinical practices, the before and after improvements in practices, the value attributed by physicians to recommendations, the user's platform experience, the educational benefits according to medical students, and the organizational benefits according to stakeholders. The knowledge gained during each phase will be applied on an iterative and continuous basis to all other phases over a period of 2 years.

Results: This project was funded in April 2018 by the Fonds de soutien à l'innovation en santé et en services sociaux for 24 months. Ethics approval has been attained, the study began in June 2018, the data collection will be complete at the end of December 2019, and the data analysis will start in winter 2020. Both major city hospitals in the Outaouais region, Quebec, Canada, have agreed to participate in the project.

Conclusions: If results show preliminary efficacy and usability of the system, a large-scale implementation will be conducted.

International Registered Report Identifier (IRRID): PRR1-10.2196/11754

(JMIR Res Protoc 2019;8(3):e11754) doi: 10.2196/11754 


\section{KEYWORDS}

knowledge translation; practice guideline; community medicine; group practice; evidence-based medicine; clinical decision making; educational technology; decision support systems, clinical

\section{Introduction}

\section{Background}

The rapid advancements in health care can make it difficult for general physicians and specialists alike to keep their knowledge up to date. In medicine today, there are deficiencies in the application of knowledge translation (KT) in clinical practice. The Canadian Institutes of Health Research (CIHR) defines knowledge translation as "a dynamic and iterative process that includes synthesis, dissemination, exchange and ethically sound application of knowledge to improve the health of Canadians, provide more effective health services and products, and strengthen the health care system" [1].

$\mathrm{KT}$ is of critical importance, considering the numerous gaps between what we know and the actual care delivered. The CIHR has come to the conclusion that "it has become clear that the creation of new knowledge often does not, on its own, lead to widespread implementation or impacts on health," [2].

In fact, the best evidence and best practices promoted by scholarly institutions and organizations are not always implemented, and some patients do not receive the most appropriate treatment. According to the Choosing Wisely campaign, it is estimated that up to $30 \%$ of examinations, treatments, and interventions performed in Canada are potentially useless or harmful [3-5]. Some studies demonstrated that $30 \%$ of patients in Ontario underwent unnecessary cardiac testing and blood analysis before a low-risk noncardiac surgical intervention $[4,6]$. Still, other studies have shown that up to $50 \%$ of trauma patients passing through the emergency do not receive all the prescribed treatments because of a lack of KT [7]. In other instances, from the expectations in regard, a prescribed test or a specific treatment is not aligned with evidence [8].

\section{Adoption of Clinical Recommendations and Guidelines Into Practice}

Throughout the world, including Canada, it is increasingly recognized that some medical procedures are unnecessary and provide no added value to the treatment [3]. These unnecessary medical procedures, which may not even address patient need, then increases pressures on the health care system's resources, reduces the quality of care, adds to patient stress, and exposes them to other potential risks $[9,10]$. The context described leads to the delivery of less efficient care for the patients exposing them to potential risks and stress [11]. Knowledge creation (ie, primary research), knowledge distillation (ie, the creation of systematic reviews and guidelines), and knowledge dissemination (ie, appearances in journals and presentations) are not enough on their own to ensure the use of knowledge in decision making [12]. It might be possible to guide the clinicians with a platform that proposes better KT and knowledge-to-action tools and really permits adoption in the clinical setting of recognized and approved clinical recommendations and guidelines. This has the potential to improve not only patient care but also the doctor-patient relationship which is based on communication, trust, and information exchange.

\section{Selection and Adaptation of Recommendations}

The Choosing Wisely campaign aims to help clinical practitioners and patients engage in dialogue about unnecessary examinations, treatments, and interventions and to make stronger and more efficient choices regarding quality care. This initiative is now implemented in 18 countries across the world, including Canada, where several recommendations have been issued pertaining to a wide range of clinical specialties, which enable an improved information exchange on best practices [13-15]. Several studies have demonstrated the relevance of their implementation in various clinical practices [16-17]. Like the Choosing Wisely campaign, the Institut national d'excellence en santé et en services sociaux (INESSS) mission is to promote clinical excellence and the efficient use of resources in the health and social services sector [18]. KT is also an integral part of their mission in "fostering the implementation of the recommendations and practice guides, using various information, knowledge transfer and awareness tools, p. 3" [19]. The INESSS also develops clinical recommendations and clinical practical guidelines intended for various communities of practice $(\mathrm{CoP})$, supported by evidence, experiential, and contextual data provided by medical professionals [20].

\section{Problem}

The challenge for the health care system is to help physicians adequately implement exemplary practices. For professional guidelines to be implemented and to improve the quality of care, it is essential that doctors become aware of the existence of these practices through appropriate methods of dissemination and implementation in day-to-day practice.

Furthermore, the transfer of theoretical knowledge and practical experience from one context to another is a focus in medical education [21-23]. This is a major concern in professional sectors and is central to the debate surrounding reforms. According to Kontoghiorghes [24], only $10 \%$ to $15 \%$ of learning translates from training to clinical practice. It is, therefore, essential to focus on the capacity to mobilize and combine knowledge to efficiently address new situations [25]. The mobilization resulting from the creation of a community of practice could promote learning and promote working with other health care professionals to solve concrete clinical problems [25]. Collaborative learning reinforces learned knowledge and encourages practical changes. For this reason, knowledge and expertise sharing between professionals and between clinical $\mathrm{CoP}$ is a recognized strategy to bring change to clinical practice [26,27].

Some models proposed in recent years promote the development of $\mathrm{CoP}$ and the continuity of patient-centered care [28-33]. These models aim at creating proactive, interdisciplinary professional teams and $\mathrm{CoP}$ who interact at various levels of the health care 
system. Studies have demonstrated the added value through the quality of interventions [34-36] of this organizational system. Integrated CoP would support clinical practitioners across various clinical settings in carrying out their daily activities and developing better patient-centric practices.

A CoP is defined as a group of individuals who are interacting to share information, experiences, models, views, advices, and best practices, as well as to solve problems and extend their knowledge in an area of practice in which they share a common interest [37]. Each member of a CoP is supported by a peer group belonging to an area of expertise or a professional practice where he can ask questions, share, and create new knowledge. Relationships with other CoP can also be established. In that respect, the creation of integrated CoP would enable the support of clinical practitioners in their daily activities as well as the growth and development of best practices. However, to make that a reality, an integrative model favoring the implementation of a knowledge-sharing structure between members of a CoP must be used to promote the emergence of collective intelligence.

Information technology (IT)-enabled CoP can support the knowledge learning and sharing activities within interdisciplinary health care teams. A study based on the Hoyman model demonstrated how computer applications can ensure the continuity and flow of the care [38].

KT tools and access to the guidelines can guide and improve physician decision-making processes depending on specific clinical situations of the patient. These tools can provide them with the available options for care, ultimately helping them promote a more efficient professional practice [26,27,39-41]. Scientific studies are published; best practices are documented; and, however, they are slow to be implemented. We are trying to evaluate if an innovative solution would allow for the application and integration of this knowledge into clinical practice. Interventions supported by IT can promote the creation, access, and application of clinical recommendations, care protocols, and regulations, as well as best practices, bringing KT to practice.

IT-enabled CoP can support learning and knowledge sharing within health care teams as well as promote best practices in a variety of clinical areas [26,27,40-42]. Wikis are being used to encourage and make it easier for clinical practitioners to share their knowledge and expertise [43-45]. Wikis can also help users adapt their knowledge for local contexts, making it more relevant and user-friendly [46,47] and to encourage collaboration between patients and clinical practitioners when developing support tools for patients $[48,49]$. As such, several authors suggested exploring collaborative Web-based platforms to share, create, and update content of clinical decision-assistance systems [46,50-53].

Systematic reviews have demonstrated the value of support tools for integrated clinical approaches [54]. Studies have also shown that the mere availability of Web-based resources is not sufficient. Even if clinical practitioners could reliably find the answers to their questions in about $50 \%$ of cases, for some reason, they do not follow through on the inquiry. Researchers suggest that technological solutions should provide access to high-quality evidence, as per the just-in-time principles, in the clinical decision-making process [55].

\section{Technological Solution: Software for the Evolution of Knowledge in MEDicine}

An innovative platform was created in the Outaouais Region in Quebec, Canada, in 2014. Initially used in the emergency area, this platform is now being assessed at the institutional level and is an integral part of the Centre intégré de santé et des services sociaux de l'Outaouais and Relations and Educational Research Department (RERD) approach. Software for the Evolution of Knowledge in MEDicine (SEKMED) is an interactive and dynamic working Web platform employing a multidimensional approach to knowledge, which considers the various dimensions linked to clinical practice such as scientific, organizational, professional, and experiential. The solution also allows collaboration and interactions through an iterative and continuous process of knowledge generation supported by the involvement of CoP.

The platform aims to facilitate the coordination of efforts deployed by members of a CoP, the accreditation and standards bodies, within an advanced Wiki-type tool dedicated to the creation, aggregation, and updating of interactive resources supporting the patient's clinical history intake, physical examination, differential diagnosis consideration, take over, and therapeutic or orientation processes by the clinical practitioners. Moreover, these resources are, then, made available, as per the just-in-time principles, directly in the clinical practitioners' processes using an ontological recognition engine which recognizes the terms associated with resources.

SEKMED assists clinical practitioners in their efforts to stay up-to-date and enables the integration of best practices as well as a better use of diagnostic and therapeutic resources. This project is destined to clinical practitioners but it can be interfaced with other health professions. There is an introductory video about the SEKMED platform [56].

Figure 1 illustrates the dashboard of SEKMED. The platform is designed in 9 sections.

Note that every section of the menu could be accessed by clicking in the SEKMED logo so that we can choose the appropriate section.

SEKMED aims at giving the clinician a representation of all the different elements that constitute its practice and facilitate the exchange with the community they are a part of. Those elements are represented in the different sections of the platform and are represented in the dashboard that we see in Figure 1. We will give a brief description for those sections, but the main focus of SEKMED is to facilitate the creation of interactive resources that support the different clinical processes, the discussion of those resources to improve them and validate them at a higher level, and to give just-in-time access to high-quality evidence in the context of patient care decision making. 
Figure 1. View of the platform dashboard.

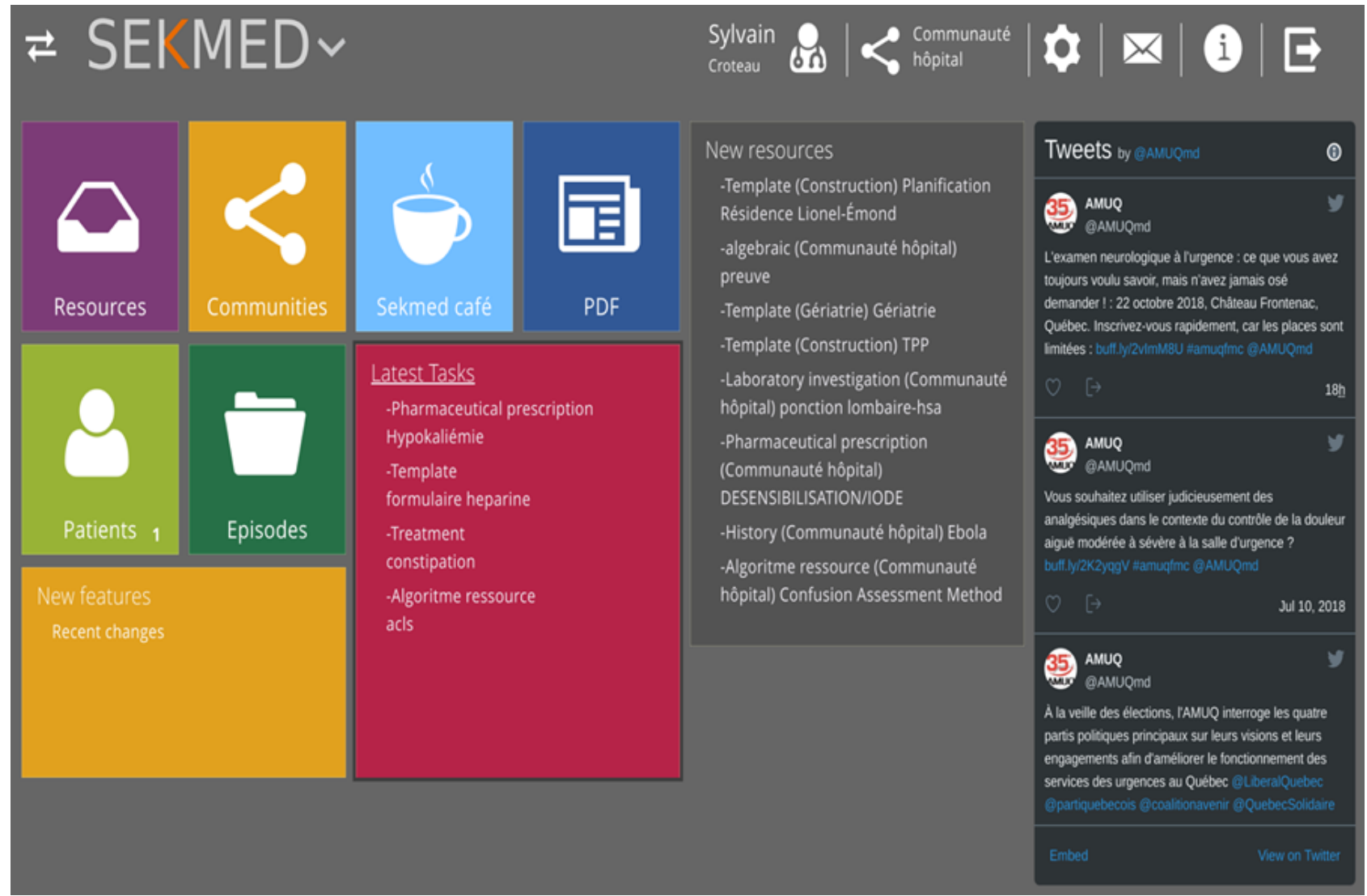

The following is a brief description of every section:

1. Resources: Here we can search for specific resources in one community or in other communities. Resources are built by the community with tools that are provided. They are formatted in a way to be immediately clinically useful. A resource could be an interactive template for history taking, physical examination, investigation, treatment, and recommendation to patients. It can also be references or educational videos that are provided in the clinical process, following the just-in-time principle. Filters could be applied during that search (type of resource, owner of the resource, and community). This process is completely distinct from the discovery of resources in the clinical setting. It is also where one can decide to add a resource. It is where the process of creation happens.

2. Communities: A list of all communities, my own communities, and pending request to adhere to one. The concept of community is important when we understand that the content that will be made available to the clinician is dependent on the fact that he or she is a member of one of them specifically.

3. SEKMED Café: A section where you can interact with your community. (Chat, message from the community, from the center where the clinician is working, a forum for longer discussion around subjects proposed by the members, a humor section, a list of the members, and a means of communication between members).

4. PDF: A section facilitating storage of PDF. From there, they can be made available to the communities. Note that most resources are not PDF, but it is often the start of the evolution from a more static to fully interactive template.

5. Patients: Index of existing patients.

6. Episodes: When a patient is selected, an episode is created for every specific encounter. Here, we can find a list of the still opened episodes, or search for one based on different criteria.

7. Latest Tasks: A list of the resources a community would like to see implemented. Each task links to a real document. This document only has a title and, in some cases, instructions for specific objectives associated. This document, in task, is then attributed or available to the members of the community of practice as a specific project.

8. New resources: A list of the most recent resources created.

9. Tweets: The Twitter feed of the community.

The SEKMED platform allows the creation of different kinds of resources, permitting the integration recommendations from normative or accrediting bodies. As shown in Figure 2, we see the implementation of a compass kind of resources. This type of resources informs the clinician about one specific recommendation of the campaign, Choosing Wisely. 
Figure 2. Integration of clinical recommendation.

<. Référence
abscess - (-)2018/10/16 - Version : 1 non approuvé

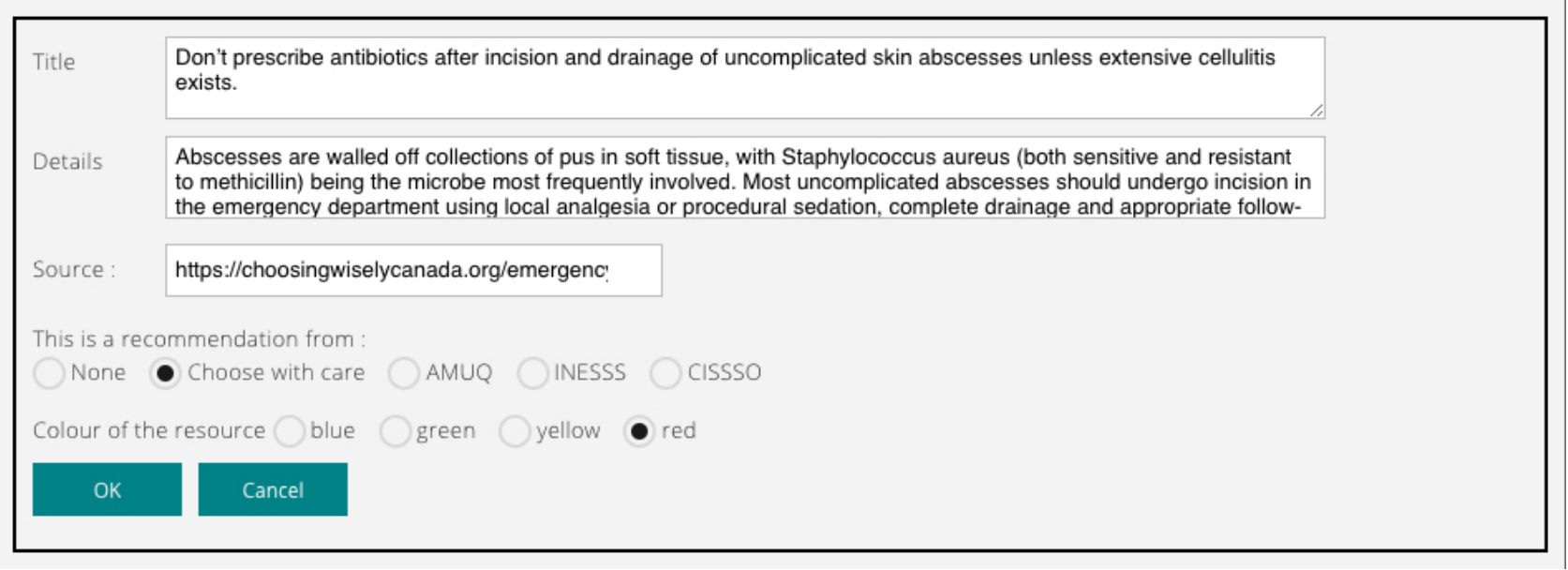

As shown in Figure 2, the title is the specific recommendation made by the normative body, the details represent the justification for the recommendation, there is and shall always be a link to the source of the information, a specific element of the resources permit the insertion of that link, there is a list of the normative or accrediting bodies from which to choose, this selection will also insert the logo of the later in the resource itself. There is a choice of color providing a visual clue as to the fact that something should not be done (red), should be done (green), or one should be careful about something (yellow), and there is also neutral powder blue for more information. That kind of resource is inserted into a template for a specific condition (Figure 3). When the template is used, the information reaches the clinician in its process. Figure 3 is a template for abscess with the usual questions, the technique for drainage, and the specific recommendation for not prescribing antibiotics in uncomplicated cases.

Figure 3. Template for abscess.

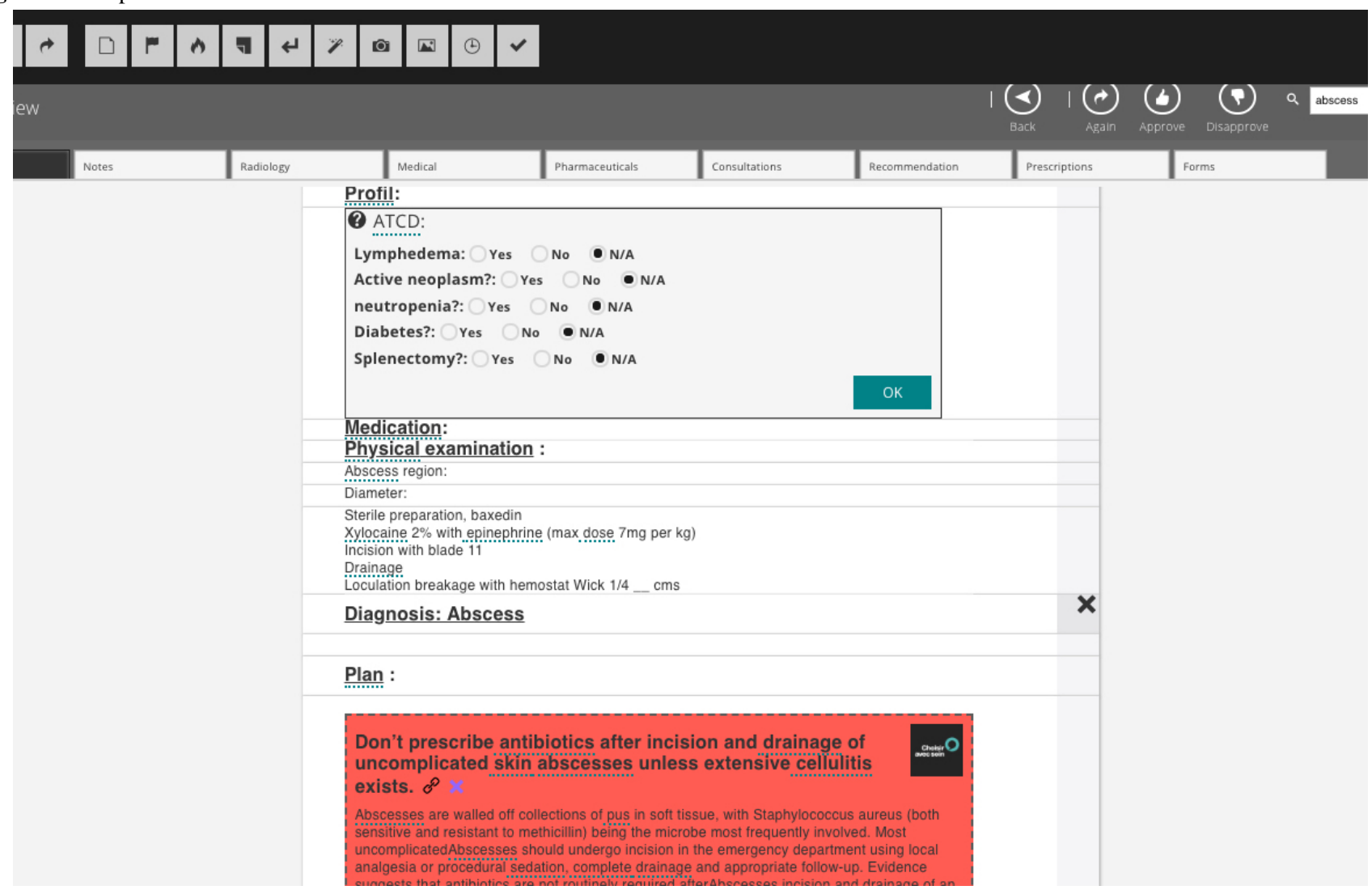


Figure 4. Recommendation from Institut national d'excellence en santé et en services sociaux (INESSS) for antibiotic treatment of sinusitis in children.

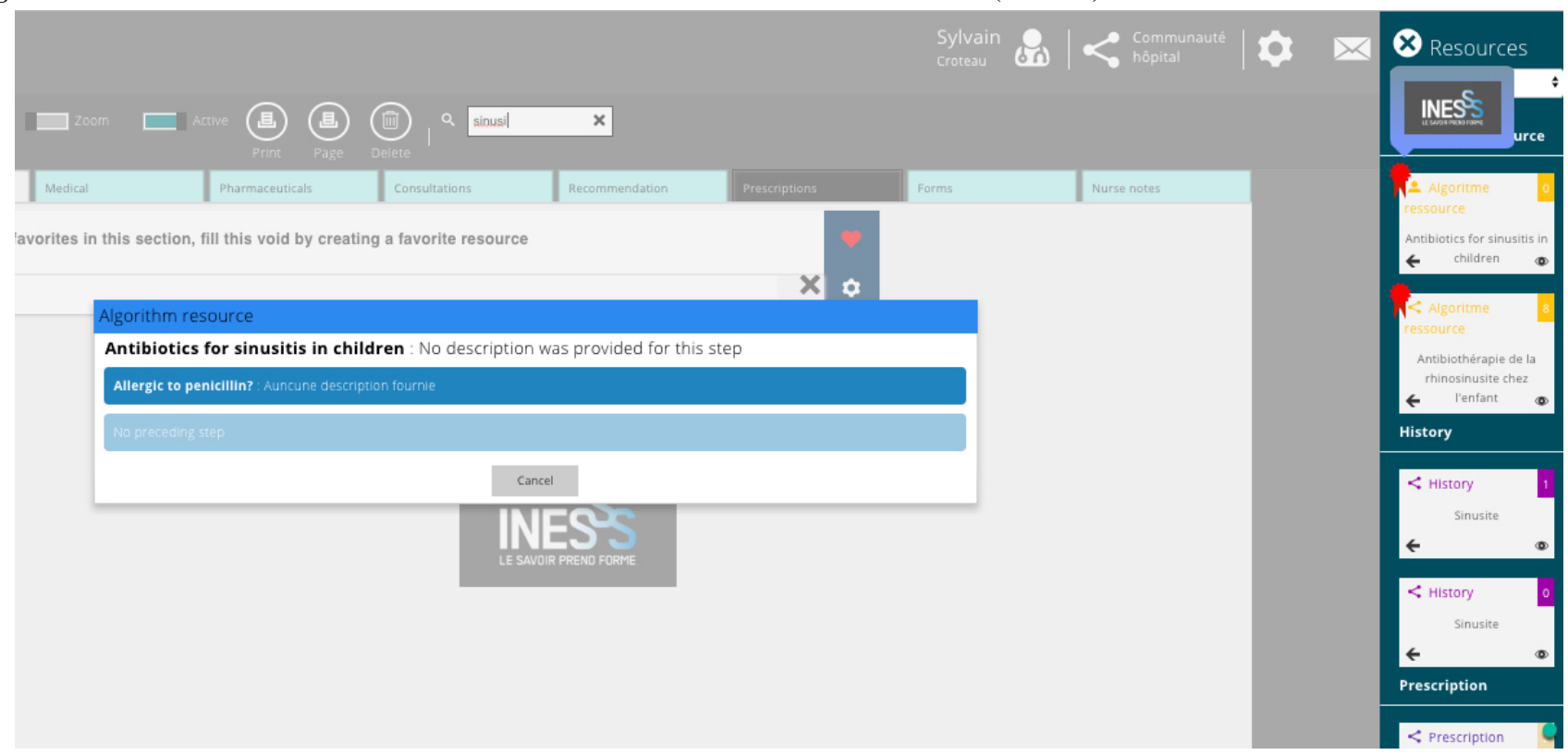

In certain cases, a full template or an algorithm could represent the recommendation of a normative body or an organization (Figure 4). It is then possible to identify resources that would have been validated at a high level by the application of a certificate. Here, a recommendation from the INESSS for the antibiotic treatment of sinusitis in children is presented as an algorithm. The certificate identifies those resources that come from normative of accrediting bodies in comparisons with the one that is created by the individuals in the community and have not gone through a process of intensive review and accreditation.

The certification needs to go to a review committee. The editing process is then blocked for the CoP. The certificate is set in advance, and the process for adding it is fairly simple.

\section{Objective}

The main objective of the pilot project is to assess the usefulness of the SEKMED platform in the implementation of medical recommendations recognized by the members of CoP, accreditation bodies (Association des médecins d'urgence du Québec or AMUQ), a campaign such as Choosing Wisely and standards bodies (INESSS) in clinical practice in real health care settings within the province of Quebec, Canada.

As part of the project, SEKMED will be assessed with $3 \mathrm{CoP}$ : (1) emergency physicians, (2) general medicine patient care unit physicians, as well as (3) external students and residents studying family medicine. Group 1 will be composed of 20 emergency physicians from the Hull Hospital and the Gatineau Hospital. Group 2 will have 20 patient care unit physicians from the Hull Hospital, and the third group will consist of approximately 10 external students and residents in family medicine from McGill University.

\section{Methods}

\section{Validation and Evaluation Methodology in a Real Caregiving Situation}

The project will focus strictly on (1) the research over a 24-month period, (2) the ethical and scientific endorsement of the project; (3) the employment of students; (4) the recruitment and training of participants; (5) the initial implementation of the 6 specific objectives through the analysis and interpretation of quantitative and qualitative data generated during the study; (6) continuous improvement; and (7) the dissemination of results within health care work environments as well as stakeholders and academic audiences.

The project will be completed in 4 phases (Figure 5). The knowledge gained during each phase will be applied on an iterative and continuous basis to all other phases over a 2-year period.

Figure 5. Research program.

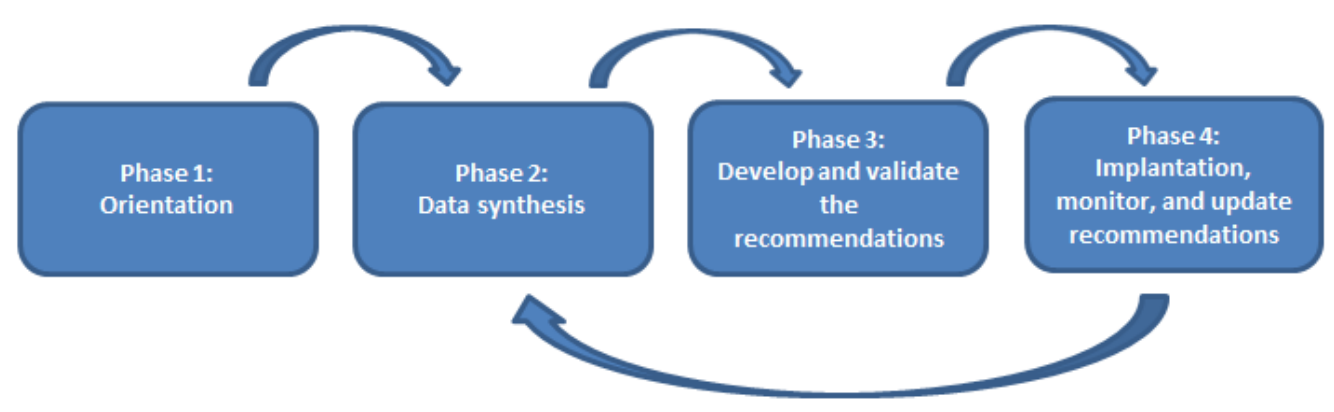




\section{Phase 1: Orientation}

This will consist in the consultation and mobilization of participants in the $3 \mathrm{CoP}$ to better understand the culture, practical settings, values, and preferences, as well as to identify their local decision-making needs at the clinical and practical level. Three work teams will then be created to represent each CoP: (1) emergency physicians; (2) patient care unit physicians; as well as (3) external students and residents in family medicine. Each community will be represented by a voluntary champion. All participants will complete training during this phase to familiarize themselves and master the SEKMED platform's functions. Each will receive a user guide with up-to-date content presenting among other things, video clips and screenshots to ensure a better understanding of the platform.

\section{Phase 2: Data Synthesis}

This will aim to rigorously collect, integrate, and synthesize the recommendations provided by the members of each community of practice, accreditation bodies (AMUQ), and standards bodies (INESSS and Choosing Wisely). Recommendations are based on 3 types of data: scientific, contextual, and experiential. An initial information search will be conducted with each team to identify the educational and informational content, templates, forms, follow-up sheet, decision-making algorithms, and other relevant resources used by the CoP. A second information search will be undertaken with accreditation and standards bodies only with the vision to compile a comprehensive list of recommendations for each specialty.

\section{Phase 3: Develop and Validate the Recommendations}

This will consist in mobilizing work teams to (1) collect and integrate scientific information, within the implementation context (contextual data) and practical experience context (experiential data), and better understand the values and preferences of each community of practice; (2) verify if the recommendations are available or not. If they are available via the accreditation and/or standards bodies, they can be considered as they stand or be adapted for local usage; (3) propose recommendations in a concise manner that are lacking and have not been listed by members of each CoP, by accreditation bodies, or by standards bodies but are deemed useful, relevant, acceptable, and applicable in the field by teams; (4) select recommendations from a list provided by accreditation and standards bodies that meet the CoP's clinical and practical needs; and (5) review and validate all recommendations that are considered essential to the practice and relevant to be applied and monitored on the SEKMED platform (Phase 4).

\section{Phase 4: Implantation, Monitor, and Update Recommendations}

In the final phase of the project, recommendations will be implemented, monitored, and updated. The implementation step aims to integrate, disseminate, and transfer recommendations across the SEKMED platform so that users may use them in their own CoP. Implementation support strategies will be available at this stage to promote ownership and facilitate the dissemination of the recommendations. The monitoring step will measure the degree of implementation of recommendations and their impact on clinical practices, care, and services management as well as the health and well-being of populations. Finally, the last step consists in making regular updates with working teams, ensuring continuous access and use of the best evidence and the recommendations provided by accreditation and standards bodies in clinical practice by sharing and making them available. Following phase 4 , there will be an iterative and continuous process, starting at phase 2 , throughout the project.

\section{Data Collection Methods}

The 4 phases described above will enable us to meet our 6 specific research objectives. The recommended data collection methodology aims to achieve deliverables based on qualitative and quantitative methods. This triangulation of methods is vital for an understanding of complex phenomena, and it allows data enhancements, questioning, monitoring, and verification [57]. Some authors suggest that the triangulation of data sources, which compares data produced by 2 or several different and independent methods, increases the interpretive power [58]. This method, whether parallel or sequential, seeks using different measures and observations, to reduce bias in each method. The goal is to exploit the complementary nature of methodological processes to get the very best out of them.

\section{Specific Objective 1}

This objective was to measure the integration of recommendations in clinical practices. This objective will demonstrate through SEKMED the uptake of medical recommendations in clinical practices. This will enable us to determine if users really take ownership and integrate the recommendations into their daily work. To do so, we will export the SEKMED data in a Microsoft Excel file to produce descriptive statistics. The information provided by the data will allow us to measure the monthly progress of the following indicators:

1. The number of recommendations used by each physician in clinical practice.

2. Percentage of specific recommendations used at specific clinical situations,

3. Percentage of physicians who are still using recommendations in clinical practice.

\section{Specific Objective 2}

This objective was to measure the before and after improvements in practices. The objective aims to compare improvements in practices, before and after the intervention, by using medical recommendations. We will be using the same approach as Specific Objective 1 for the data extraction, analysis, and processing.

The following indicators will be measured:

1. The number of new recommendations integrated into the platform that is used by physicians;

2. Average and median time required for the integration of recommendations in a work environment.

\section{Specific Objective 3}

This objective was to measure the value attributed by physicians to recommendations. This objective will appraise the overall 
value (experience and satisfaction) attributed by physicians to recommendations provided by members of the community of practice, as well as accreditation and standards bodies in their field of practice. A total of 4 focus groups will be held during the project. The data collected with the first 2 specific objectives will be discussed at each focus group. This approach aims to foster reflective practices in providing an opportunity to step back and collectively review the experiences and the participants' point of view on this practice and how it facilitates the KT process.

Our approach must be flexible to produce the desired change and to adapt to the situation while allowing knowledge development, experience sharing, and ideas exchange to ultimately find solutions to common health care problems [59-61]. The assessment of this intervention will be completed using a mixed approach, which combines a qualitative approach with a quasi-experimental-type quantitative approach focused on the measured experience and satisfaction levels. Using this approach, we will be able to determine the extent to which reflective learning can facilitate the transfer and use of recommendations made by the CoP.

\section{Specific Objective 4}

This objective was to measure the user's platform experience. This objective will measure the user's experience with the platform. The user experience is defined as an individual's perception and response resulting from his or her use or the anticipated use of a system [62]. This understanding of the user experience is also essential in nature for these organizations who wish to offer interfaces that meet the various users' evolving needs in an efficient manner [63]. As part of our project, we are developing a conceptual model of the user experience based on the rich conceptual framework of IT usage prepared by Barki, Titah, and Boffo [62], which takes simultaneously into account the characteristics of the technology (eg, usability), the user (eg, expertise), and the task to achieve (eg, complexity) to better understand the concept of utilization. We will also integrate technology acceptance and utilization models based on behavioral intents which are influenced by IT usage perceptions and its usability [63-66].

The research team will administer a questionnaire after each experimental period with the tool. We have chosen to analyze the data using the partial least squares structural equation modeling (PLS-SEM) to verify and refine the proposed theoretical models. PLS-SEM is a second generation multivariate statistical analysis method. Although first generation techniques usually rely on traditional research statistical methods such as regression and analysis of the variance, second generation techniques compensate the first generation techniques' shortcomings by notably taking the errors in measurement into account. PLS is relevant for our project because it is used for exploratory assessment purposes such as the analysis of trends and the identification of relationships.

\section{Specific Objective 5}

This objective was to measure the educational benefits according to medical and external students. This objective consists of assessing the attitude and intent of external students and residents in family medicine toward the educational benefits of SEKMED. We will administer the same questionnaire used for Specific Objective 4. We will also organize focus groups to learn about the user's experience in the adaptation and learning process. A total of 4 focus groups will be held during the project.

Several studies have shown that IT promotes the adoption of a pedagogical approach which places the student or the learner at the center of the learning process. IT indeed provides the innovative means, not only for the dissemination of knowledge, but also for the exploration of learning strategies promoting competency development-access to information, real-time communication, and exchange with CoP. Many papers focus on experimentation with a Wiki, but fewer studies explain the rationale and the pedagogical foundations $[67,68]$. Several authors think it is possible to improve the teaching system on clinical reasoning by using techniques that are more efficient than conventional teaching [69]. We wish to demonstrate that SEKMED enables learning, including accompanying and complementary skills evaluation support by governing the problem-solving process and by assessing the students' and residents' ability to process the information. In that respect, SEKMED could be used as a diagnostic assessment in providing a more personalized support program to learning.

\section{Specific Objective 6}

This objective was to measure the organizational benefits according to stakeholders. This objective will assess the attitude and intent of the RERD and the stakeholders toward the changes resulting from the use of the platform and the achievement of their specific objectives. In view of the specificity of this objective and the target audience, an interview guide will be developed and validated before its use. The interview guide will measure the attitude and intent of the RERD and the stakeholders toward the changes resulting from the use of SEKMED and the achievement of their specific organizational objectives.

RERD will benefit from a tool facilitating the transfer, mobilization, and validation of knowledge gained within the organization while driving innovation. In support of all management bodies governing the clinical practice, they will be able to monitor medical and social interventions more rigorously in real time. Statistical functions and the ability to extract granular data actually make it possible to assess all medical acts, track changes, and implement best practices while also validating the application and the relevancy of the recommendations issued by the organization or the accreditation and standards bodies. In other words, all actions performed by caregivers become traceable and measurable.

Stakeholders supporting the clinical practices are the Directorate of Professional Services, Directorate of Multidisciplinary Services, and the Nursing Directorate. As mentioned above, SEKMED has the ability to extract data at the granular level, which reduces the amount of time they require to complete specific tasks. As an example, the review of medical records, also known as audits, will be improved owing to the ability to track all actions performed by a health care professional. SEKMED also promotes the dissemination, among clinical practitioners, of clinical tools and best practices, thus simplifying 
their implementation and training needs. To conclude, these data allow the development of follow-up and performance indicators that will facilitate the monitoring activities performed by management bodies supporting the clinical practice.

\section{Results}

This project was funded in April 2018 by the Fonds de soutien à l'innovation en santé et en services sociaux for 24 months. Ethics approval has been attained, the study began in June 2018, the data collection will be complete at the end of December 2019 , and the data analysis will start in winter 2020. Both major city hospitals in the Outaouais region, Quebec, Canada, have agreed to participate in the project.

\section{Discussion}

If results show preliminary efficacy and usability of the system, a large-scale implementation will be conducted.
The expected benefits generated by this protocol on the improvement of care and service delivery are as follows:

1. The use of better evidence and recommendations issued by the accreditation and standards bodies in clinical practice, by continuously sharing and making them available within the context of their implementation.

2. To gain efficiencies in the dissemination, usage, and update of institutional protocols.

3. Gaining efficiencies for clinical practitioners.

4. The rationalization of the resource and budget use.

5. The efficient harmonization of practices.

6. The improvement of the teaching quality.

7. The use of granular data to assess the quality of the act as well as administrative and research purposes.

\section{Acknowledgments}

The SEKMED pilot project has received funding from the Fonds de soutien à l'innovation en santé et en services sociaux under grant agreement number 1-01.

\section{Authors' Contributions}

VN and SC were the lead in designing and writing the protocol for obtaining the funding. VN was responsible for revising the manuscript multiple times for methodological, conceptual, and intellectual content. The final version of the manuscript was approved by all authors.

\section{Conflicts of Interest}

None declared.

\section{Multimedia Appendix 1}

Peer-review report from the granting agency.

[PDF File (Adobe PDF File), 156KB-Multimedia Appendix 1]

\section{Multimedia Appendix 2}

Scientific validation from the Scientific Committee of the Centre intégré de santé et des services sociaux de l'Outaouais in support of the peer-review report from the granting agency.

[PDF File (Adobe PDF File), 582KB-Multimedia Appendix 2]

\section{References}

1. Straus SE, Tetroe J, Graham ID, editors. Knowledge translation: what it is and what it isn't. In: Knowledge Translation in Health Care: Moving From Evidence to Practice. New Jersey: BMJ Books; Aug 19, 2013.

2. Canadian Institutes of Health Research (CIHR). Guide to Knowledge Translation Planning at CIHR: Integrated and End-of-Grant Approaches. Ottawa: CIHR; 2012:60.

3. Silverstein W, Lass E, Born K, Morinville A, Levinson W, Tannenbaum C. A survey of primary care patients' readiness to engage in the de-adoption practices recommended by Choosing Wisely Canada. BMC Res Notes 2016 Jun 10;9:301 [FREE Full text] [doi: 10.1186/s13104-016-2103-6] [Medline: 27286651]

4. Kirkham KR, Wijeysundera DN, Pendrith C, Ng R, Tu JV, Laupacis A, et al. Preoperative testing before low-risk surgical procedures. CMAJ 2015 Aug 11;187(11):E349-E358 [FREE Full text] [doi: 10.1503/cmaj.150174] [Medline: 26032314]

5. Yong PL, Saunders RS, Olsen LA, editors. The Healthcare Imperative Lowering Costs and Improving Outcomes Workshop Series Summary. Washington (DC): National Academies Press (US); 2010.

6. Kirkham KR, Wijeysundera DN, Pendrith C, Ng R, Tu JV, Boozary AS, et al. Preoperative laboratory investigations: rates and variability prior to low-risk surgical procedures. Anesthesiology 2016 Apr;124(4):804-814 [FREE Full text] [doi: 10.1097/ALN.0000000000001013] [Medline: 26825151] 
7. Atkins D, Eccles M, Flottorp S, Guyatt GH, Henry D, Hill S, GRADE Working Group. Systems for grading the quality of evidence and the strength of recommendations I: critical appraisal of existing approaches The GRADE Working Group. BMC Health Serv Res 2004 Dec 22;4(1):38 [FREE Full text] [doi: 10.1186/1472-6963-4-38] [Medline: 15615589]

8. Rappolt S, Mitra AL, Murphy E. Professional accountability in restructured contexts of occupational therapy practice. Can J Occup Ther 2002 Dec;69(5):293-302. [doi: 10.1177/000841740206900505] [Medline: 12501454]

9. Detsky AS, Verma AA. A new model for medical education: celebrating restraint. J Am Med Assoc 2012 Oct 3;308(13):1329-1330. [doi: 10.1001/2012.jama.11869] [Medline: 23032547]

10. Berrington de González A, Mahesh M, Kim KP, Bhargavan M, Lewis R, Mettler F, et al. Projected cancer risks from computed tomographic scans performed in the United States in 2007. Arch Intern Med 2009 Dec 14;169(22):2071-2077 [FREE Full text] [doi: 10.1001/archinternmed.2009.440] [Medline: 20008689]

11. Büla C, Ruedin HJ, Carron PN. Rev Med Suisse. 2012. Personnes âgées aux urgences : défis actuels et futurs URL: https:/ /www.revmed.ch/RMS/2012/RMS-350/Personnes-agees-aux-urgences-defis-actuels-et-futurs [accessed 2018-07-20] [WebCite Cache ID 713RwciH3]

12. Straus SE, Tetroe J, Graham I. Defining knowledge translation. CMAJ 2009 Aug 4;181(3-4):165-168 [FREE Full text] [doi: 10.1503/cmaj.081229] [Medline: 19620273 ]

13. Gnjidic D, Elshaug AG. De-adoption and its 43 related terms: harmonizing low-value care terminology. BMC Medicine 2015 Oct 20;13(1):273. [doi: 10.1186/s12916-015-0511-4] [Medline: 26486727]

14. Glauser W. Choosing wisely campaign well received. CMAJ 2014 May 13;186(8):E239-E240 [FREE Full text] [doi: 10.1503/cmaj.109-4779] [Medline: 24710907]

15. Cassel CK, Guest JA. Choosing wisely: helping physicians and patients make smart decisions about their care. JAMA 2012 May 2;307(17):1801-1802. [doi: 10.1001/jama.2012.476] [Medline: 22492759]

16. Middleton JL. Putting choosing wisely into practice. Am Fam Physician 2018 Apr 1;97(7):432-433. [Medline: 29671554]

17. Wintemute KL, Wilson L, Levinson W. Choosing wisely in primary care: moving from recommendations to implementation. Can Fam Physician 2018 May;64(5):336-338 [FREE Full text] [Medline: 29760252]

18. Institut national d'excellence en santé et services sociaux (INESSS). 2018. About the Institut. Mission URL: http://www. inesss.qc.ca/en/about-us/about-the-institut.html [accessed 2018-07-20] [WebCite Cache ID 713SWcedU]

19. Institut national d'excellence en santé et services sociaux (INESSS). LegisQuébec. Québec: Québec Official Publisher; 2018. Act respecting The Institut national d'excellence en santé et en services sociaux URL: http://www. legisquebec.gouv.qc.ca/en/showdoc/cs/i-13.03 [accessed 2018-07-20] [WebCite Cache ID 713SusmfA]

20. Boughrassa F, Framarin A. Institut national d'excellence en santé et services sociaux (INESSS). Québec: INESSS; 2014 Apr. Recommandations québécoises: usage judicieux de 14 analyses biomédicales URL: https://www.inesss.qc.ca/fileadmin/ doc/INESSS/Webinaires/Juin 2014/INESSS Rapport-Usage judicieux 14 analyses biomedicales.pdf [accessed 2018-07-20] [WebCite Cache ID 713SusmfA]

21. Le Boterf DG. Construire les compétences individuelles et collectives [Build Individual and Collective Skills]. Paris: Eyrolles; 2000.

22. Le Boterf DG. Repenser la compétences. Pour dépasser les idées reçues propositions [Rethinking Competence: To Overcome the Received Ideas: 15 Proposals]. Paris: Eyrolles; Sep 23, 2000:140.

23. Packer M. The problem of transfer, and the sociocultural critique of schooling. J Learn Sci 2001 Oct;10(4):493-514. [doi: 10.1207/S15327809JLS1004new 4]

24. Kontoghiorghes C. Reconceptualizing the learning transfer conceptual framework: empirical validation of a new systemic model. Int J Train Dev 2004 Aug 11;8(3):210-221. [doi: 10.1111/j.1360-3736.2004.00209.x]

25. Rey B, Carette V, Defrance A, Kahn S, Meirieu P. Les compétences à l'école : Apprentissage et évaluation. Bruxelles: De Boeck Université; 2012:160.

26. Balas EA, Weingarten S, Garb CT, Blumenthal D, Boren SA, Brown GD. Improving preventive care by prompting physicians. Arch Intern Med 2000 Feb 14;160(3):301-308. [doi: 10.1001/archinte.160.3.301] [Medline: 10668831]

27. Buntinx F, Winkens R, Grol R, Knottnerus JA. Influencing diagnostic and preventive performance in ambulatory care by feedback and reminders. A review. Fam Pract 1993 Jun;10(2):219-228. [doi: 10.1093/fampra/10.2.219] [Medline: 8359615]

28. Bonomi AE, Wagner EH, Glasgow RE, VonKorff M. Assessment of chronic illness care (ACIC): a practical tool to measure quality improvement. Health Serv Res 2002 Jun;37(3):791-820 [FREE Full text] [doi: 10.1111/1475-6773.00049] [Medline: 12132606]

29. Clauser SB, Wagner EH, Aiello Bowles EJ, Tuzzio L, Greene SM. Improving modern cancer care through information technology. Am J Prev Med 2011 May;40(5 Suppl 2):S198-S207 [FREE Full text] [doi: 10.1016/j.amepre.2011.01.014] [Medline: 21521595]

30. McCorkle R, Ercolano E, Lazenby M, Schulman-Green D, Schilling LS, Lorig K, et al. Self-management: enabling and empowering patients living with cancer as a chronic illness. CA Cancer J Clin 2011;61(1):50-62 [FREE Full text] [doi: 10.3322/caac.20093] [Medline: 21205833]

31. Wagner EH. The role of patient care teams in chronic disease management. Br Med J 2000 Feb 26;320(7234):569-572 [FREE Full text] [Medline: 10688568] 
32. Wagner EH. Academia, chronic care, and the future of primary care. J Gen Intern Med 2010 Sep;25(Suppl 4):S636-S638 [FREE Full text] [doi: 10.1007/s11606-010-1442-6] [Medline: 20737241]

33. Wagner EH, Austin BT, Davis C, Hindmarsh M, Schaefer J, Bonomi A. Improving chronic illness care: translating evidence into action. Health Aff (Millwood) 2001;20(6):64-78 [FREE Full text] [Medline: 11816692]

34. Cheadle A, Schwartz PM, Rauzon S, Beery WL, Gee S, Solomon L. The Kaiser Permanente community health initiative: overview and evaluation design. Am J Public Health 2010 Nov;100(11):2111-2113. [doi: 10.2105/AJPH.2010.300001] [Medline: 20935261]

35. Crooks P. Managing high-risk, high-cost patients: the southern california kaiser permanente experience in the medicare ESRD demonstration project. Perm J 2005;9(2):93-97 [FREE Full text] [doi: 10.7812/TPP/04-119] [Medline: 21660174]

36. Saward EW. The relevance of the Kaiser-Permanente experience to the health services of the Eastern United States. Bull N Y Acad Med 1970 Sep;46(9):707-717 [FREE Full text] [Medline: 5271308]

37. Lowry SJ, Loggers ET, Bowles EJ, Wagner EH. Evidence gaps in advanced cancer care: community-based clinicians' perspectives and priorities for comparative effectiveness research. J Oncol Pract 2012 May;8(3 Suppl):28s-33s [FREE Full text] [doi: 10.1200/JOP.2012.000569] [Medline: 22942821]

38. Demiris G, Thompson HJ, Reeder B, Wilamowska K, Zaslavsky O. Using informatics to capture older adults' wellness. Int J Med Inform 2013 Nov;82(11):e232-e241 [FREE Full text] [doi: 10.1016/j.ijmedinf.2011.03.004] [Medline: 21482182]

39. White S, Bissell P, Anderson C. Patients' perspectives on cardiac rehabilitation, lifestyle change and taking medicines: implications for service development. J Health Serv Res Policy 2010 Apr;15(Suppl 2):47-53. [doi: 10.1258/jhsrp.2009.009103] [Medline: 20176661]

40. Garg AX, Adhikari NK, McDonald H, Rosas-Arellano MP, Devereaux PJ, Beyene J, et al. Effects of computerized clinical decision support systems on practitioner performance and patient outcomes: a systematic review. J Am Med Assoc 2005 Mar 9;293(10):1223-1238. [doi: 10.1001/jama.293.10.1223] [Medline: 15755945]

41. Shojania KG, Jennings A, Mayhew A, Ramsay CR, Eccles MP, Grimshaw J. The effects of on-screen, point of care computer reminders on processes and outcomes of care. Cochrane Database Syst Rev 2009 Jul 8(3):CD001096 [FREE Full text] [doi: 10.1002/14651858.CD001096.pub2] [Medline: 19588323]

42. Wensing M, Grol R. Single and combined strategies for implementing changes in primary care: a literature review. Int $\mathbf{J}$ Qual Health Care 1994 Jun;6(2):115-132. [Medline: 7953212]

43. Barwick MA, Peters J, Boydell K. Getting to uptake: do communities of practice support the implementation of evidence-based practice? J Can Acad Child Adolesc Psychiatry 2009 Feb;18(1):16-29 [FREE Full text] [Medline: 19270845]

44. Dijkstra R, Wensing M, Thomas R, Akkermans R, Braspenning J, Grimshaw J, et al. The relationship between organisational characteristics and the effects of clinical guidelines on medical performance in hospitals, a meta-analysis. BMC Health Serv Res 2006 Apr 28;6:53 [FREE Full text] [doi: 10.1186/1472-6963-6-53] [Medline: 16646968]

45. Heilman JM, Kemmann E, Bonert M, Chatterjee A, Ragar B, Beards GM, et al. Wikipedia: a key tool for global public health promotion. J Med Internet Res 2011 Jan 31;13(1):e14 [FREE Full text] [doi: 10.2196/jmir.1589] [Medline: 21282098]

46. Berner ES. Agency for Healthcare Research and Quality. 2009 Jun. Clinical Decision Support Systems: State of the Art URL: https://healthit.ahrq.gov/sites/default/files/docs/page/09-0069-EF 1.pdf [accessed 2018-07-20] [WebCite Cache ID $713 \mathrm{gXfw} 20]$

47. Graham ID, Tetroe J. Some theoretical underpinnings of knowledge translation. Acad Emerg Med 2007 Nov;14(11):936-941 [FREE Full text] [doi: 10.1197/j.aem.2007.07.004] [Medline: 17967955]

48. Gupta S, Wan FT, Newton D, Bhattacharyya OK, Chignell MH, Straus SE. WikiBuild: a new online collaboration process for multistakeholder tool development and consensus building. J Med Internet Res 2011 Dec 8;13(4):e108 [FREE Full text] [doi: 10.2196/jmir.1833] [Medline: 22155694]

49. van de Belt TH, Faber MJ, Knijnenburg JM, van Duijnhoven NT, Nelen WL, Kremer JA. Wikis to facilitate patient participation in developing information leaflets: first experiences. Inform Health Soc Care 2014 Mar;39(2):124-139. [doi: 10.3109/17538157.2013.872107] [Medline: 24517459]

50. Wright A, Bates DW, Middleton B, Hongsermeier T, Kashyap V, Thomas SM, et al. Creating and sharing clinical decision support content with web 2.0: issues and examples. J Biomed Inform 2009 Apr;42(2):334-346 [FREE Full text] [doi: 10.1016/j.jbi.2008.09.003] [Medline: 18935982]

51. Sittig DF, Wright A, Simonaitis L, Carpenter JD, Allen GO, Doebbeling BN, et al. The state of the art in clinical knowledge management: an inventory of tools and techniques. Int J Med Inform 2010 Jan;79(1):44-57 [FREE Full text] [doi: 10.1016/j.ijmedinf.2009.09.003] [Medline: 19828364]

52. Cresswell KM, Bates DW, Phansalkar S, Sheikh A. Opportunities and challenges in creating an international centralised knowledge base for clinical decision support systems in ePrescribing. BMJ Qual Saf 2011 Jul;20(7):625-630. [doi: 10.1136/bmjqs.2010.048934] [Medline: 21606472]

53. Sittig DF, Wright A, Osheroff JA, Middleton B, Teich JM, Ash JS, et al. Grand challenges in clinical decision support. J Biomed Inform 2008 Apr;41(2):387-392 [FREE Full text] [doi: 10.1016/j.jbi.2007.09.003] [Medline: 18029232]

54. Haute Autorité de Santé. 2000 Jan 1. Effectiveness of methods of implementing medical recommendations [Effectiveness of methods of implementing medical recommendations] URL: https://www.has-sante.fr/portail/jcms/c_430282/fr/ efficacite-des-methodes-de-mise-en-oeuvre-des-recommandations-medicales[WebCite Cache ID 713hPTlH4] 
55. Del Fiol G, Workman TE, Gorman PN. Clinical questions raised by clinicians at the point of care: a systematic review. JAMA Intern Med 2014 May;174(5):710-718. [doi: 10.1001/jamainternmed.2014.368] [Medline: 24663331]

56. SEKMED. 2018. Video of SEKMED platform URL: http://www.screencast.com/t/LNrYkkuow [accessed 2018-07-20] [WebCite Cache ID 713hj3b7K]

57. Denzin NK. The Research Act: A Theoretical Introduction to Sociological Methods. Piscataway, New Jersey: Aldine Transaction; Mar 9, 2009:379.

58. Creswell JW. Research Design: Qualitative, Quantitative, and Mixed Methods Approaches (2nd Edition). California: SAGE Publications; 2002:246.

59. Walsh K, McAllister M, Morgan A. Using reflective practice processes to identify practice change issues in an aged care service. Nurse Educ Pract 2002 Dec;2(4):230-236. [doi: 10.1016/S1471-5953(02)00023-9] [Medline: 19036304]

60. Stringer ET. Action research. Third edition. Thousand Oaks: Sage Publications; 2007:279.

61. Kemmis S, McTaggart R, Nixon R. The Action Research Planner: Doing Critical Participatory Action Research. New York: Springer; 2014:200.

62. Barki H, Titah R, Boffo C. Information system use-related activity: an expanded behavioral conceptualization of individual-level information system use. Inf Syst Res 2007 Jun;18(2):173-192. [doi: 10.1287/isre.1070.0122]

63. Davis F. Perceived usefulness, perceived ease of use, and user acceptance of information technology. Manag Inf Syst Q 1989 Sep;13(3):319-340. [doi: 10.2307/249008]

64. Brown S, Dennis A, Venkatesh V. Predicting collaboration technology use: Integrating technology adoption and collaboration research. J Manag Inf Syst 2010 Dec;27(2):9-54. [doi: 10.2753/MIS0742-1222270201]

65. Venkatesh V, Morris MG, Davis GB, Davis FD. User acceptance of information technology: toward a unified view. Manag Inf Syst Q 2003 Sep;27(3):425-478. [doi: 10.2307/30036540]

66. Davis FD, Bagozzi RP, Warshaw PR. User acceptance of computer technology: a comparison of two theoretical models. Manag Sci 1989 Aug;35(8):982-1003. [doi: 10.1287/mnsc.35.8.982]

67. Ruth A, Houghton L. The wiki way of learning. Australas J Educ Technol 2009;25(2):135-152. [doi: 10.14742/ajet.1147]

68. Elgort I, Smith AG, Toland J. Is wiki an effective platform for group course work? Australas J Educ Technol 2008;24(2):195-210. [doi: 10.14742/ajet.1222]

69. Vanpee D, Godin V, Lebrun M. Améliorer l'enseignement en grands groupes à la lumière de quelques principes de pédagogie active [Improving large groups teaching on the basis of some active learning principles]. Int Fr J Med Educ 2008;9(1):32-41 [FREE Full text]

\section{Abbreviations}

AMUQ: Association des médecins d'urgence du Québec

CIHR: Canadian Institutes of Health Research

CoP: Communities of practice

INESSS: Institut national d'excellence en santé et en services sociaux

IT: information technology

KT: knowledge translation

PLS-SEM: partial least squares structural equation modeling

RERD: Relations and Educational Research Department

SEKMED: Software for the Evolution of Knowledge in MEDicine

Edited by G Eysenbach; submitted 31.07.18; peer-reviewed by B Alper; comments to author 12.10.18; revised version received
17.11.18; accepted 13.12.18; published 11.03.19
Please cite as:
Nabelsi V, Croteau S
An Evidence-Based Health Care Knowledge Integration System: Assessment Protocol
JMIR Res Protoc $2019 ; 8(3):$ :el1754
URL: $\underline{\text { http://www.researchprotocols.org/2019/3/e11754/ }}$
doi: $\underline{10.2196 / 11754}$
PMID: $\underline{30855235}$

(C) Véronique Nabelsi, Sylvain Croteau. Originally published in JMIR Research Protocols (http://www.researchprotocols.org), 11.03.2019. This is an open-access article distributed under the terms of the Creative Commons Attribution License (https://creativecommons.org/licenses/by/4.0/), which permits unrestricted use, distribution, and reproduction in any medium, provided the original work, first published in JMIR Research Protocols, is properly cited. The complete bibliographic information, 
a link to the original publication on http://www.researchprotocols.org, as well as this copyright and license information must be included. 